- Research Paper

\title{
Analysis on the Distribution Regularity of Fire Load in Hotel Buildings
}

\author{
Wei Gao' ${ }^{1}$ Jinhua Sun ${ }^{2}$, Ying Zhang ${ }^{3}$ and Jianzhong Rong ${ }^{2}$ \\ ${ }^{1}$ Department of Chemical System Engineering, School of Engineering, The University of Tokyo, Japan \\ ${ }^{2}$ State Key Laboratory of Fire Science, University of Science and Technology of China, China \\ ${ }^{3}$ School of Natural Resources and Environmental Engineering, Wuhan University of Technology, China
}

\begin{abstract}
This paper presents survey results on fire loads distributions for hotel buildings in the cities of Hefei, Lanzhou, Shenyang, Chengdu, Yantai and Tianjin surveyed in China. Details of the survey methodology, data collection and processing are given. Furthermore, the influence of the hotel rating, room type, region and room floor area on fire loads are discussed in detail. Based on the probability statisticsand test of normality, the fire load densities of all the surveyed hotels show a lognormal distribution with the mean value of $349.2 \mathrm{MJ} / \mathrm{m}^{2}$, the maximum value of $886.4 \mathrm{MJ} / \mathrm{m}^{2}$, the minimum value of $117.8 \mathrm{MJ} / \mathrm{m}^{2}$, and the standard deviation of 142.1. The fire loads obtained from the survey have been compared with those of similar surveys in other countries. According to the survey results, the fire dynamical theory and characteristics of building fire, the evaluation methods of the fire duration time and the collapse probability of building caused by fire are also developed in this paper. The statistical parameters of the fire load presented in this paper will be useful in the design of fire prevention and fire fighting measures of hotel buildings.
\end{abstract}

Keywords: Fire load, Fire load density, Lognormal distribution, Fire duration time, Collapse probability

\section{INTRODUCTION}

Fire load is basic data to the performance-based fire protection design regarding the overall development stage of fire as well as the intensity and duration of the fire $[1,2]$. Knowledge of the statistical distribution of the fire load is essential for designing a building against fire. A review of the current state of knowledge indicates that considerable progress is yet to be made in correctly assessing the design fire load.

The loads are random in nature, time dependent and often depend on living habits, living standards and many cultural and social aspects. It is thus necessary to conduct load surveys periodically to review the validity of prevailing loads, etc. Surveys have shown that fire load is dependent on occupancy, for example, residences, offices, libraries and hotels have different kinds of fire loads. At present only meager data exist concerning the fire load in buildings $[3,4,5]$. 
This paper presents the results of a survey, which was conducted in the Chinese cities of Hefei, Lanzhou, Chengdu, Shenyang, Yantai and Tianjin(which was surveyed by Cai Yun [6]) to characterize fire loads in hotel buildings. The survey includes double rooms, quad rooms, six beds rooms, deluxe suites, dining halls, conference rooms and scriptoriums.

\section{FIRE LOAD}

Fire load is the starting point for estimating the potential size and severity of a fire, and thus the endurance required of walls, columns, doors, floor-ceiling assemblies and other parts of the enclosing compartment. The term "fire load" is defined as the total heat content upon complete combustion of all the combustible material contained inside a building or the fire compartment. In that case, the heat content per unit area is called the fire load density. The higher its value, the greater the potential fire severity and damage as the duration of the burning period of the fire is considered proportional to fire load, it is given as [6]:

$$
q=\frac{\sum M_{V} \Delta h_{c}}{A_{f}}
$$

Where $q$ is the fire load density, $\left(\mathrm{MJ} / \mathrm{m}^{2}\right) . M_{v}$ is the total weight of each single combustible item in the fire compartment, $(\mathrm{kg}) . \Delta h_{c}$ is the effective calorific value of each combustible item, $(\mathrm{MJ} / \mathrm{kg}) . A_{f}$ is the floor area of the fire compartment, $\left(\mathrm{m}^{2}\right)$.

\section{SURVEY METHODOLOGY}

Determining the fire loads in a building involves determining the floor area of the fire compartment, the mass of all the different types of combustibles and their effective calorific values. The floor area of a compartment can be determined by measuring its dimension. The mass of an item in a compartment can be determined by weighing it (weighing technique) or by determining its volume and identifying its density (inventory technique). In this survey, all the techniques have been employed. The direct weighing method was used for the items that could easily be weighed, such as chairs and garbage cans. The inventory method was used for the items such as large objects and built-in shelves. In this method, dimensions of items were measured and their volume was calculated $[1,7,8]$. The mass was then computed by multiplying the volume by the density of the material [9]. The densities of some typical materials are shown in Tables 1-3. The calorific values of combustible substances given in Table 4 were used in the fire load calculations [10]. For some special combustible substances such as computers, the heat of combustion could be determined by consulting literatures. 
Table 1 The densities of common wooden materials

\begin{tabular}{cccc}
\hline Materials & Density $\left(\mathrm{kg} / \mathrm{m}^{3}\right)$ & Materials & Density $\left(\mathrm{kg} / \mathrm{m}^{3}\right)$ \\
\hline korean pine & 440.00 & sophora japonica & 722.00 \\
cinnamomum camphora & 535.00 & quercus mongolica & 766.00 \\
liquidambar formosana & 588.00 & quercus acutissima & 930.00 \\
birch & 635.00 & dalbergia hupeana & 987.00 \\
\hline
\end{tabular}

Table 2 The densities of common fabric materials

\begin{tabular}{cccc}
\hline Materials & Density $\left(\mathrm{g} / \mathrm{m}^{2}\right)$ & Materials & Density $\left(\mathrm{g} / \mathrm{m}^{2}\right)$ \\
\hline lining fabric & 99.00 & twill $(100 \%$ cotton $)$ & 230.00 \\
OPTOH & 270.00 & glove fabric & 260.00 \\
disguise fabric & 244.00 & canvas & 400.00 \\
twill C50EX & 245.00 & flax & 420.00 \\
\hline
\end{tabular}

Table 3 The densities of common plastic materials

\begin{tabular}{cccc}
\hline Materials & Density $\left(\mathrm{g} / \mathrm{cm}^{3}\right)$ & Materials & Density $\left(\mathrm{g} / \mathrm{cm}^{3}\right)$ \\
\hline silicon rubber & 0.80 & phenol formaldehyde resin & $1.26 \sim 1.41$ \\
high pressure polyethylene & $0.89 \sim 0.93$ & polyvinyl fluoride & $1.30 \sim 1.40$ \\
low-pressure polyethylene & $0.92 \sim 0.98$ & PVC R & $1.38 \sim 1.50$ \\
polystyrene & $1.04 \sim 1.08$ & polyoxymethylene & $1.41 \sim 1.43$ \\
epoxy resin & $1.10 \sim 1.40$ & chlorinated polyvinyl chloride & $1.47 \sim 1.55$ \\
Polyacrylic & $1.14 \sim 1.14$ & PVDF & $1.70 \sim 1.80$ \\
\hline
\end{tabular}

Table 4 Calorific values of common combustible materials

\begin{tabular}{cccc}
\hline Materials & $\begin{array}{c}\text { Calorific } \\
\text { value(MJ/kg) }\end{array}$ & Materials & $\begin{array}{c}\text { Calorific } \\
\text { Value(MJ/kg) }\end{array}$ \\
\hline Clothes & 18.80 & Wool & 23.00 \\
Kerosene & 37.20 & ABS & 36.00 \\
Leather & 18.60 & Linoleum & 20.00 \\
LPG & 49.90 & Silk & 19.00 \\
Paper & 16.30 & Rubber & 39.50 \\
Plastic & 22.10 & Wood(average) & 18.60 \\
Epoxy Resin & 34.00 & Urea Formaldehyde Foam & 14.00 \\
\hline
\end{tabular}

For each survey, a similar procedure was followed to ensure that data were collected in a systematic and consistent fashion for all buildings. Firstly, the building name, as well as, the type of establishment, and the date of the investigation were recorded. Secondly, the dimensions of the building were measured and the types of wall, floor, and ceiling lining materials were determined and noted in the fixed fire load section of the survey form. Thirdly, all contents in the building were identified and classified. The items that could be weighed were weighed to determine their mass. If the items were made by one material, the material was determined and recorded. For the items consisting of more than one material type, the percentage of each type was determined and quantified. The mass of items that could not be weighed was determined by measuring their volume and using the density of the material to calculate their mass. For the following data analysis procedure, it was assumed that combustibles within the compartment are uniformly distributed, and that at the time of fire, all combustibles would be involved in a fire and would experience complete combustion. 


\section{SURVEY RESULTS}

The influences of hotel rating, room type, region, room floor area on fire load and the detailed analysis on the distribution regularity are presented in this section.

\subsection{Influence of Hotel Rating}

According to the consumption level, the hotels were divided into low-rating hotels, middle-rating hotels and high-rating hotels. The low-rating hotels are generally facing to the low-income population. The housing conditions are very poor, and the rooms were merely conducted preliminary internal decorations. Only common electric equipments, such as televisions exist in the rooms. The middle-rating hotels are generally facing to the general income people. The most common electric equipments exist in the rooms, such as televisions, air conditioning equipments and so on. The interior finishing materials are massive high-quality wooden materials, plastic materials, cotton ramie silk materials and other synthetic materials in the middle-rating hotels. Most of these hotels also open dining halls. The high-rating hotels are generally facing to the high expense crowd. This kind of hotels open all kinds of halls, such as specialty restaurants, dancing halls, coffee shops, grand auditoriums, assembly halls and so on. The rooms usually have multiple functions. Except for the common electric equipments, there also exist office supplies in the rooms.

For of the three different rating hotels, a summary of statistical calculations is shown in Table 5. Considering all hotels together, the mean fire load in the low-rating hotels, middle-rating hotels and high-rating hotels were obtained as $223.13 \mathrm{MJ} / \mathrm{m}^{2}$, 329.70 MJ/m $\mathrm{m}^{2}$ and $408.27 \mathrm{MJ} / \mathrm{m}^{2}$, respectively. The fire load density increases with the raising rating of the hotels. This is due to the interior finishing materials which are massive high-quality wooden materials, plastic materials, cotton ramie silk materials and other synthetic materials in some middle-rating and high-rating hotels, which result in the greater fire load density. In addition, with the popularity of electrification and automation, a large number of electrical equipments such as refrigerators, televisions and vacuum cleaners were arranged in the hotels, which also increases the fire load density. Besides, the elegant environment of high-rating hotels also attracted some companies to carry on their daily office in them. Therefore, some modern office equipments, such as photocopiers, fax machines, computers, paper shredders and so on are employed in the offices, which increases the fire load density as well. 
Table 5 Influence of grade on fire load $\left(\mathrm{MJ} / \mathrm{m}^{2}\right)$

\begin{tabular}{cccc}
\hline Statistical & Low- Rating & Middle- Rating & High- Rating \\
Parameter & Hotel & Hotel & Hotel \\
\hline Number & 29 & 64 & 82 \\
Mean & 223.13 & 329.70 & 408.27 \\
Median & 165.40 & 318.70 & 405.20 \\
Variance & 9523.80 & 11205.32 & 22219.35 \\
Std. Deviation & 97.59 & 105.86 & 149.06 \\
Minimum & 117.80 & 167.20 & 141.50 \\
Maximum & 426.70 & 698.60 & 886.40 \\
Range & 308.90 & 531.40 & 744.90 \\
Interquartile Range & 160.40 & 123.00 & 182.30 \\
Skewness & 0.70 & 1.34 & 0.85 \\
Kurtosis & -0.85 & 2.35 & 1.05 \\
\hline
\end{tabular}

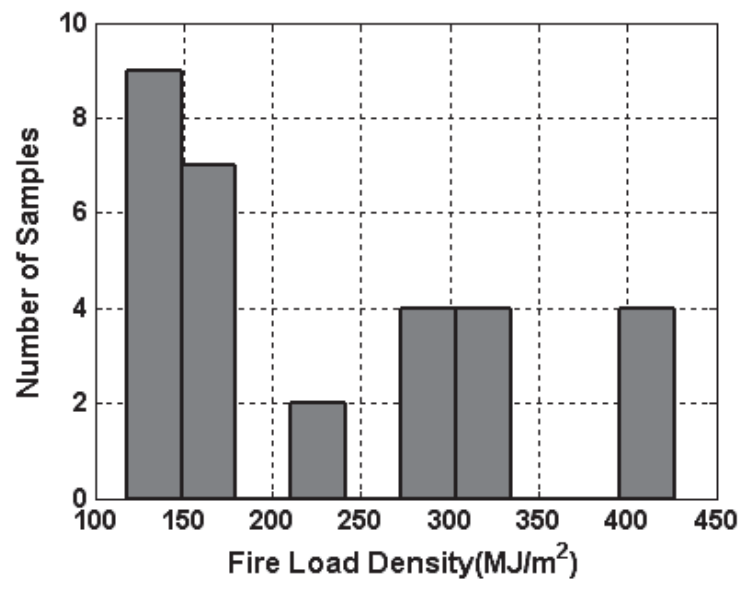

Figure 1 Fire load histogram----low-rating hotel

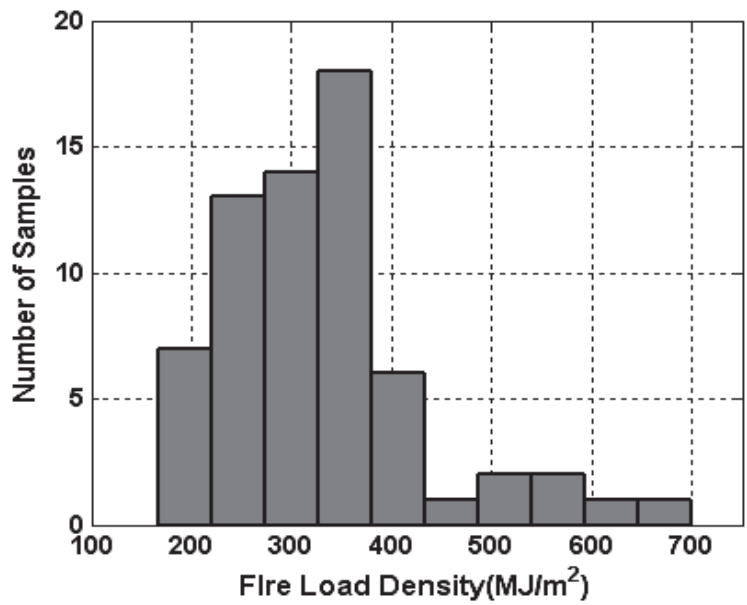

Figure 2 Fire load histogram----middle-rating hotel 


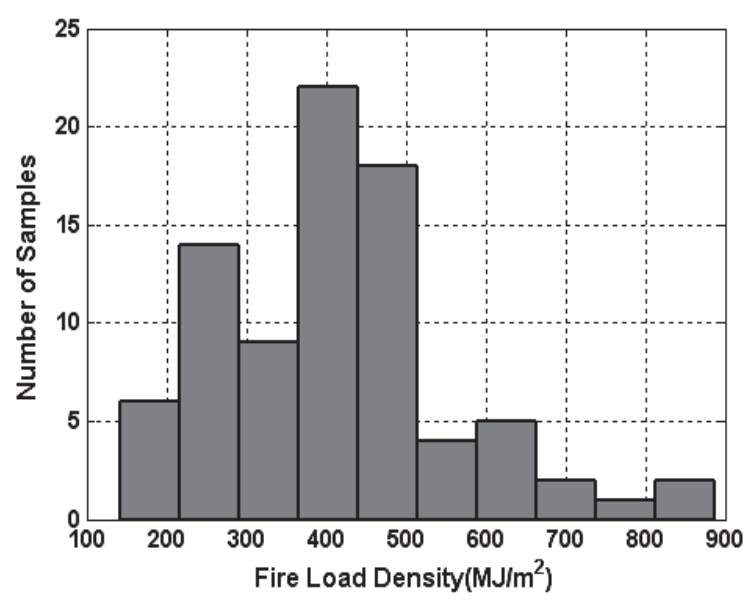

Figure 3 Fire load histogram----high-rating hotel

\subsection{Influence of Room Type}

Room type may play a significant effect on the composition and magnitude of the fire load in hotel buildings. For each room type, a summary of statistical calculations is also shown in Table 6. For all rooms, the mean and standard deviation of fire load were obtained as $349.2 \mathrm{MJ} / \mathrm{m}^{2}$ and 142.12 , respectively. The maximum fire load of $886.40 \mathrm{MJ} / \mathrm{m}^{2}$ was encountered in a double room. Deluxe suites were most heavily loaded, followed by double rooms. The least mean load was found in the six beds room and dining hall. However, the variation of standard deviations is not different from the mean fire load. The standard deviation of scriptorium was most heavily loaded, while the dining hall is the least value. As for the double rooms and deluxe suites which have limited floor areas, the interior finishing materials adopted massive high-quality wooden materials, plastic materials, cotton ramie silk materials and other synthetic materials, meanwhile, up-market combine-units, sofa, refrigerators, televisions, air conditioning equipments and vacuum cleaners were widely arranged in the hotel buildings. These resulted in the increasing fire loads. The quad rooms and six beds rooms were widely investigated in the low-grade hotels, and the fire loads are lower, which is due to the tatty interior decorations. The larger floor areas in the conferences, dining halls and scriptoriums limited the value of fire loads. 
Table 6 Influence of room type on fire load $\left(\mathrm{MJ} / \mathrm{m}^{2}\right)$

\begin{tabular}{ccccc}
\hline \multirow{2}{*}{ Room Type } & \multicolumn{4}{c}{ Fire Load $\left(\mathrm{MJ} / \mathrm{m}^{2}\right)$} \\
\cline { 2 - 5 } & Minimum load & Maximum load & Mean load & $\begin{array}{c}\text { Standard } \\
\text { deviation of load }\end{array}$ \\
\hline Double room & 167.20 & 886.40 & 395.20 & 133.10 \\
Quad room & 117.80 & 329.80 & 204.00 & 57.90 \\
Six beds room & 127.00 & 161.00 & 137.60 & 12.60 \\
Deluxe suite & 228.30 & 511.80 & 401.10 & 71.70 \\
Dining hall & 193.30 & 297.30 & 238.40 & 26.80 \\
Conference room & 358.60 & 446.90 & 389.40 & 30.70 \\
Scriptorium & 141.50 & 815.70 & 377.00 & 217.00 \\
All rooms & 117.80 & 886.40 & 349.20 & 142.12 \\
\hline
\end{tabular}

\subsection{Influence of Region}

Figure 4 shows the minimum, maximum, mean and standard deviation of the hotels fire load in different cities. The distribution shows that the fire loads are different even for the same kind buildings. The maximum, mean and standard deviation of fire load all achieved the maximum value in Shenyang, while these parameters in Yantai are lowest. Different living habits, living standards, culture and social aspects in different cities resulted in the different fire loads.

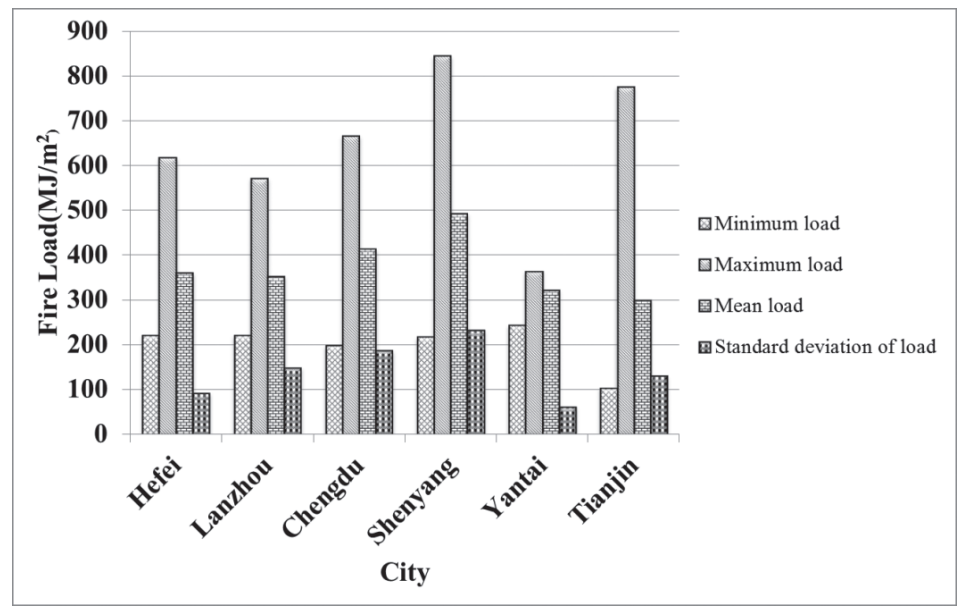

Figure 4 Fire load histogram----influence of region

\subsection{Influence of Room Floor Area}

Because of the huge differences on floor area for different type rooms, the double rooms were selected to examine the influence of room floor area on fire loads. Figures 5-7 show the maximum, mean and standard deviation of fire load with the floor area of all the rooms taken together. The maximum fire load, the mean fire load and the standard deviation of fire load decrease with the increase in floor area of rooms up to $25 \mathrm{~m}^{2}$, but thereafter they show increase trend with further increase in floor area. For the same 
rating hotels (low-rating hotels, middle-rating hotels) with limited floor areas, the furnishings and electric appliances in large and small rooms are similar. Therefore, the fire loads gradually decrease with the increasing floor area. But for some middle-rating hotels and high-rating hotels which have larger floor areas, the quantities of furnishings and electric appliances increase with the increasing floor area, which forms great fire loads in the hotel buildings.

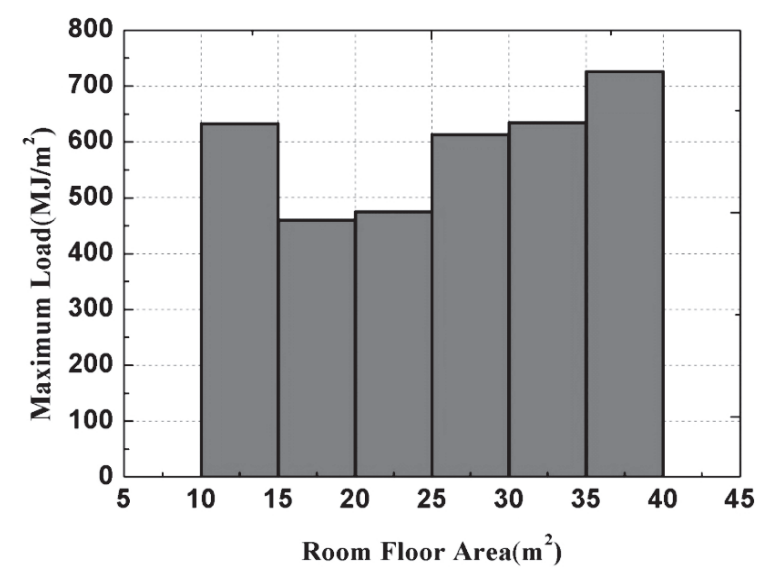

Figure 5 Influence of room floor area on maximum fire load

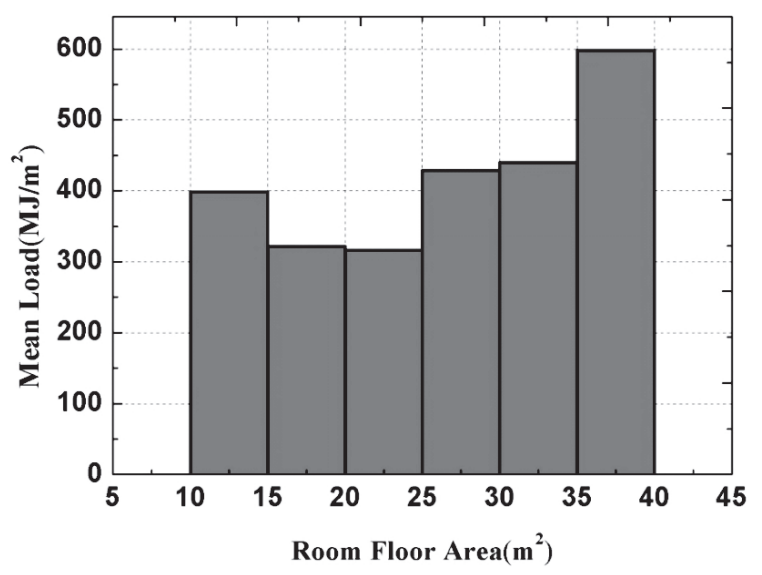

Figure 6 Influence of room floor area on mean fire load 


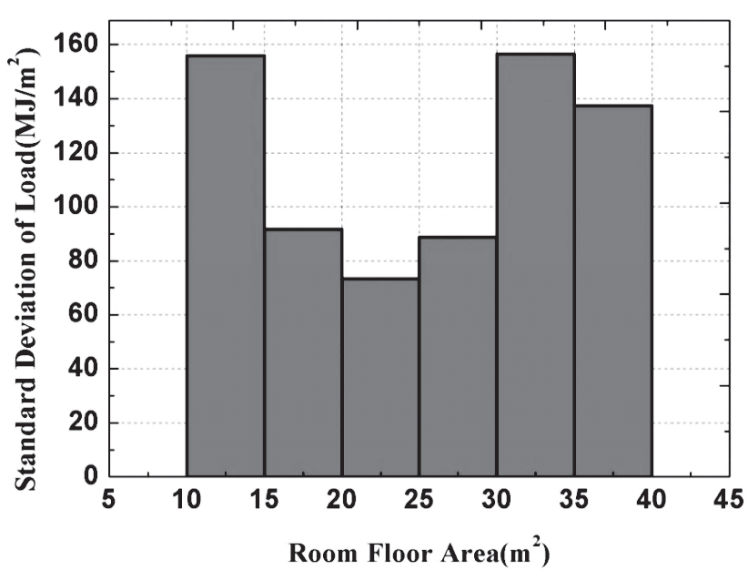

Figure7 Influence of room floor area on standard deviation of fire load

\subsection{Statistical Interpretation of Fire Load Density}

Figure 8 shows the frequency distribution of fire load densities of all the surveyed hotels. It can be seen that the frequency distribution is positively skewed indicating that on the whole, high values of fire load have low occurrence. The distribution regularity is not the normal distribution that other type buildings obey. The characteristics of the fire load for all the hotels are presented in Table 7, in which the skewness is greater than zero also indicates the data collected show the right-skewed trend and may be similar to the lognormal distribution. The standard lognormal probability density function is as follows [11]:

$$
f(x)=\frac{1}{\sqrt{2 \pi} x \sigma} e^{-\frac{1}{2}\left(\frac{\ln x-\mu}{\sigma}\right)^{2}}
$$

Where $\mu$ is the population mean, $\sigma$ is the standard deviation, for the domain $0 \leq x \leq+\infty$, the parameters $\mu>0, \sigma>0$.

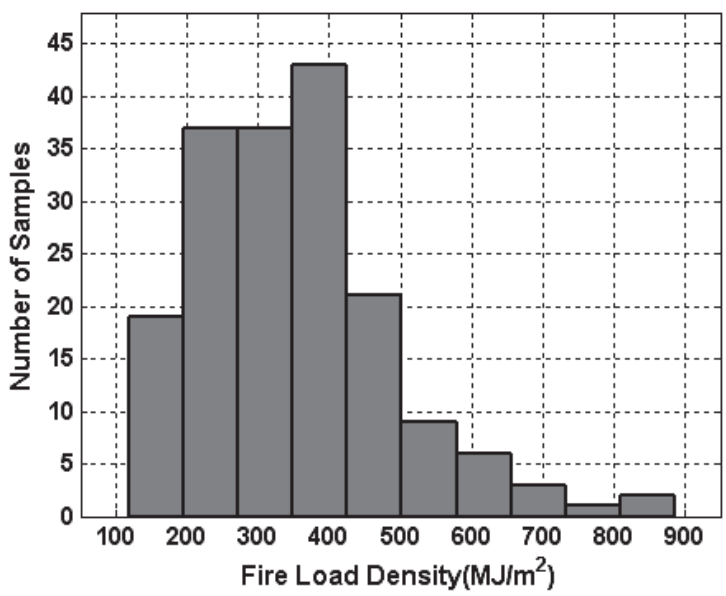

Figure 8 Frequencies of fire load density of all the surveyed hotels 
Table 7 Characteristics of the fire load for all the hotels $\left(\mathrm{MJ} / \mathrm{m}^{2}\right)$

\begin{tabular}{ccc}
\hline Statistical Parameter & Statistic & Std. Error \\
\hline Mean & 349.20 & 10.682 \\
95\% Confidence Interval for Mean Lower Bound & 328.12 & \\
Upper Bound & 370.28 & \\
5\% Trimmed Mean & 340.41 & \\
Median & 340.40 & \\
Variance & 20199.02 & \\
Std. Deviation & 142.12 & \\
Minimum & 117.8 & \\
Maximum & 886.4 & \\
Range & 768.6 & \\
Interquartile Range & 173.9 & 0.183 \\
Skewness & 0.948 & 0.363 \\
Kurtosis & 1.395 & \\
\hline
\end{tabular}

In terms of the data collected obey lognormal distribution or not, three test methods which are normal probability plot, Jarque-Bera test (JB) and Lilliefors test are presented after taking logarithm of all the data. Figure 9 shows the normal probability plot of fire load in all the hotels. It can be seen that most data conform with the expected value. The results of Jarque-Bera test and Lilliefors test are presented in Table 8 . If the result of hypothesis testing $H$ is equal to 0 , the hypothesis that the underlying distribution is a lognormal distribution could not be rejected. In the table, $P$ is the check value. JBSTAT and KSTAT are the test statistics and $C V$ is the critical value. All the three test results clearly confirm that the fire load frequencies have a lognormal distribution at the $5 \%$ significance level. The probability density function is as follows[12]:

$$
f(q)=\frac{1}{\sqrt{2 \pi} * q * 0.41} e^{-\frac{1}{2}\left(\frac{\ln q-5.78}{0.41}\right)^{2}}
$$

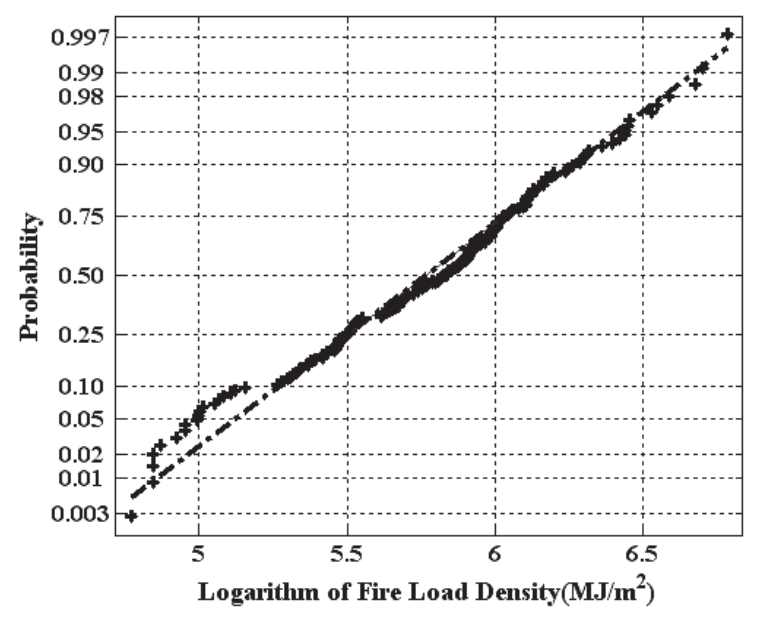

Figure 9 Normal probability plot of fire load 
Table 8 The results of Jarque-Bera test and Lilliefors test

\begin{tabular}{ccccc}
\hline Jarque-Bera test & & & & \\
DATA & $\mathrm{H}$ & $\mathrm{P}$ & JBSTAT & $\mathrm{CV}$ \\
Gaussian noise & 0 & 0.2927 & 2.0932 & 5.6458 \\
\hline Lillieforstest & & & & \\
DATA & $\mathrm{H}$ & $\mathrm{P}$ & KSTAT & $\mathrm{CV}$ \\
Gaussian noise & 0 & 0.1238 & 0.0598 & 0.0671 \\
\hline
\end{tabular}

Figure 10 shows the cumulative frequency distribution of all hotels taken together. The $50 \mathrm{th}, 80 \mathrm{th}$ and $90 \mathrm{th}$ percentile of fire load are $327.7 \mathrm{MJ} / \mathrm{m}^{2}, 457.6 \mathrm{MJ} / \mathrm{m}^{2}$ and $548.9 \mathrm{MJ} / \mathrm{m}^{2}$, respectively.

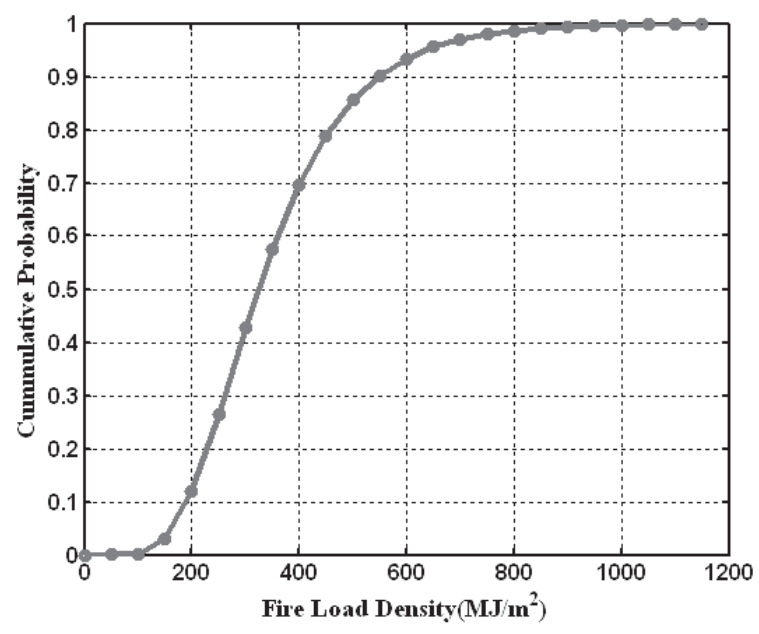

Figure 10 Cummulative frequency distribution of all hotels

\subsection{Comparison with Other Country Surveys}

The results of the present work are compared with those of the hotel building surveys in other countries. Table 9 summarizes the comparative values of the results of the present work with other country surveys[1, 6, 13, 14, 15]. It can be seen from Table 9 that the results of the present survey are considerably different from other country surveys. The differences in the results of other country surveys and those of the present one are due to the following reasons. Other country surveys were mostly conducted in the early 1990s and the results were pertinent to the hotel infrastructural facilities then existing, while the results reported in this note are for the presently prevailing conditions in China. The increasing use of massive high-quality wooden materials, plastic materials, cotton ramie silk materials and other synthetic materials in hotels may account for the greater fire load. On the other hand, different living habits, living standards and many cultural and social aspects also result in the different fire loads. 
Table 9 Comparison of fire load densities in the hotel buildings

\begin{tabular}{ccc}
\hline Survey conducted by & Mean $\left(\mathrm{MJ} / \mathrm{m}^{2}\right)$ & Standard deviation $\left(\mathrm{MJ} / \mathrm{m}^{2}\right)$ \\
\hline Mabin (1994) & 251 & 58 \\
Barnett (1984) & 263 & -- \\
F.E.D.G (1994)** & 300 & -- \\
Pettersson (1976)** & 270 & -- \\
B.S.F.S.E. (1993) & 310 & -- \\
Swedish Data* & $310^{+}$ & $92^{+}$ \\
European Data* & $310^{+}$ & $104^{+}$ \\
Present work & 349 & 142 \\
\hline
\end{tabular}

\section{FIRE DURATION TIME}

For high-rise buildings and large space buildings, the duration time is an important basis for the building fire protection design. The duration time not only depends on the fire load in the buildings, but also the spatial characteristics, opening size and position of the buildings. Assuming the consumption of combustibles during the growth period can be ignored, the fire duration time is given by the fire load density and the mass burning rate[16].

$$
t_{d u r}=\frac{W}{\dot{m}}
$$

Where $t_{d u r}$ is the fire duration time, (s). $W$ is the total weight of combustibles in the fire compartment, $(\mathrm{kg}) . \dot{m}$ is the mass burning rate, $(\mathrm{kg} / \mathrm{s})$.

During the full development period, the rate of burning is generally controlled by the ventilation conditions, the mass burning rate can be obtained by using[17]:

$$
\dot{m}=0.092 A \sqrt{H}
$$

Where $H$ is the height of the window, $(\mathrm{m})$. A is the area of the window, $\left(\mathrm{m}^{2}\right)$.

After knowing the total weight of combustibles and the mass burning rate, the fire duration time can be calculated by:

$$
t_{d u r}=\frac{A_{f} q}{0.092 A \sqrt{H}}
$$

Substituting $k$ for $\frac{A_{f}}{0.092 A \sqrt{H}}$, where $k$ which is related to the floor area, the height and area of the window is a parameter to characterize the structural features of buildings. Hence, the fire duration time can be expressed:

$$
t_{d u r}=k \cdot q
$$

The distribution regularity of fire load in the hotel buildings is lognormal distribution and the probability density function is as follows:

$$
f(q)=\frac{1}{\sqrt{2 \pi} * q * 0.41} e^{-\frac{1}{2}\left(\frac{\ln q-5.78}{0.41}\right)^{2}}
$$


After taking logarithm, the Equation 7 can be expressed as:

$$
\ln t_{d u r}=\ln k+\ln q
$$

Based on the characteristics of the normal distribution, $\ln t_{d u r}$ also obeys the normal distribution. Compared to $\ln q$, the probability density curve shifted $\ln k$ units to the right, that is :

$$
f\left(\ln t_{d u r}\right)=\frac{1}{\sqrt{2 \pi} \sigma_{\ln t_{d u r}}} \exp \left[-\frac{\left(\ln t_{d u r}-\mu_{\ln t_{d u r}}\right)^{2}}{2 \sigma_{\ln t_{d u r}}^{2}}\right]
$$

Where $\mu_{\ln t_{\text {durv }}}, \sigma_{\ln t_{\text {dur }}}$ are the mean and standard deviation of the normal distribution $f\left(\ln t_{d u r}\right)$, respectively.

The mean and standard deviation can be respectively obtained as:

$$
\begin{aligned}
& \mu_{\ln t_{d u r}}=\ln \frac{\mu_{q}}{\sqrt{1+\frac{\sigma_{q}^{2}}{\mu_{q}^{2}}}}+\ln k \\
& \sigma_{\ln t_{d u r}}=\sqrt{\ln \left(1+\frac{\sigma_{q}^{2}}{\mu_{q}^{2}}\right)}
\end{aligned}
$$

Statistical parameters of hotel buildings are presented in Table 10.

Table 10 Statistical Parameters of hotel buildings

\begin{tabular}{cccc}
\hline Building & Mean $\left(\mathrm{kg} / \mathrm{m}^{2}\right)$ & Standard deviation $\left(\mathrm{kg} / \mathrm{m}^{2}\right)$ & $k$ \\
\hline Hotel & 19.4 & 7.9 & 91.1 \\
\hline
\end{tabular}

Based on the Equation 10,11,12 and Table 10, the probability density distribution function of the fire duration time can be obtained:

$$
f\left(t_{d u r}\right)=\frac{1}{t_{d u r}} * \frac{1}{\sqrt{2 \pi} * 0.39} \exp \left[-\frac{\left(\ln t_{d u r}-7.4\right)^{2}}{2 * 0.39^{2}}\right]
$$

Figure 11 gives probability density curve versus fire duration time.

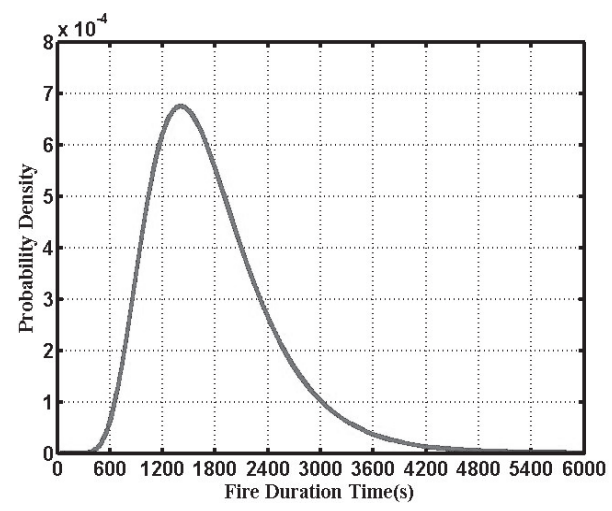

Figure 11 Probability density curve of fire duration time 
Fire load in the hotel buildings is relatively large. When fire occurs, it generates more heat and lasts for a long time.

\section{THE COLLAPSE PROBABILITY}

When fire occurs, whether the building will collapse depends on the fire duration time and the fire resistance time. When the fire duration time is more than the fire resistance time $t_{\max }$, the building will collapse. The collapse probability can be expressed in the following way $[18,19,20]$ :

$$
P_{\text {fail }}=\int_{t_{\max }}^{\infty} f\left(t_{d u r}\right) d t_{d u r}
$$

The collapse probability of hotel building can be expressed as:

$$
P_{\text {fail }}=\int_{t_{\max }}^{\infty} \frac{1}{t_{d u r}} * \frac{1}{\sqrt{2 \pi} * 0.39} \exp \left[-\frac{\left(\ln t_{d u r}-7.4\right)^{2}}{2 * 0.39^{2}}\right] d t_{d u r}
$$

Figure 12 shows the relationship between fire resistance time and the collapse probability of hotel building.

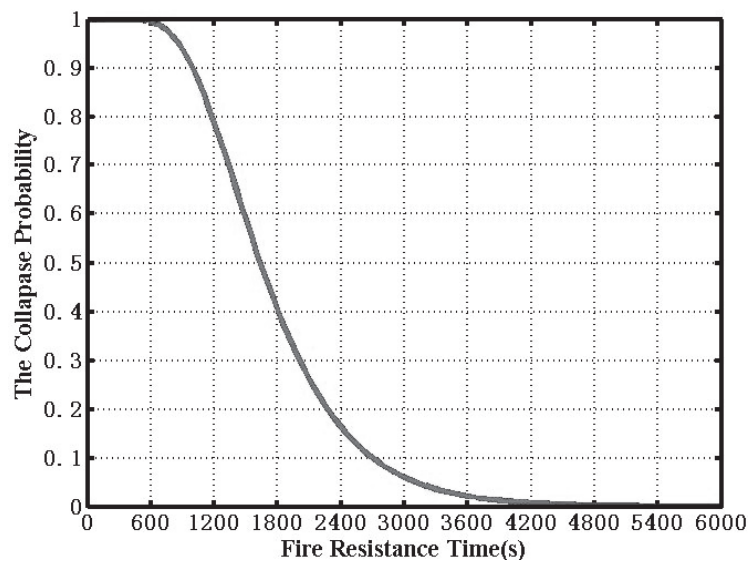

Figure 12 The collapse probability of hotel building

From Figure 12 it can be seen that, the collapse probability will decrease with the increasing fire resistance time at the mean fire duration time.

\section{CONCLUSIONS}

A study has been made into fire loads in hotel buildings of China. The effects of several factors on the fire load were considered. Based on the survey results presented herein, the following conclusions can be drawn. 
(1) In hotel buildings, the mean fire load and standard deviation of fire load increase with raising rating of the hotels.

(2) The magnitude of fire load is related to the room type. Deluxe suites are the most heavily loaded, followed by double rooms. The least mean load is the six beds room and dining hall.

(3) Fire load is also affected by the region. The maximum, mean and standard deviation of fire load all achieved the maximum value in Shenyang, while these parameters in Yantai are the lowest ones.

(4) The maximum fire load, the mean fire load and the standard deviation of fire load decrease with the increasing floor area of rooms up to $25 \mathrm{~m}^{2}$, but thereafter they show increasing trend with further increase in floor area.

(5) The fire load densities of all the surveyed hotels have a lognormal distribution with a mean value of $349.2 \mathrm{MJ} / \mathrm{m}^{2}$, a maximum value of $886.4 \mathrm{MJ} / \mathrm{m}^{2}$, a minimum value of $117.8 \mathrm{MJ} / \mathrm{m}^{2}$, and a standard deviation of 142.12 .

(6) The fire duration time and the collapse probability of building caused by fire were also developed by the corresponding calculation model.

\section{ACKNOWLEDGEMENT}

This study was supported by the Key Projects in the National Science \& Technology Pillar Program during the Eleventh Five-year Plan Period, No. 2006BAK06B02. The authors thank Prof. Dobashi and Dr. Mogi for their comments to this paper.

\section{REFERENCES}

1. H. W. Yii, Effect of Surface Area and Thickness on Fire Loads, Fire Engineering Research Report 2000/13, University of Canterbury, Mar. 2000

2. B. R. Ellingwood, Impact of Fire Exposure on Heat Transmission in Concrete Slabs, Journal of Structural Engineering, Vol. 117, Issue 6, 1870-1875, Jun. 1991

3. National Bureau of Standards, Fire Resistance Classification of Building Construction, Building Materials and Structures Report BMS 92, Washington, D.C., Oct. 1942

4. E. C. C. Choi, Data structure and data processing procedures for live loads and fire loads in office buildings, Technical Record 524, National Building Technology Centre, Sydney, 1988

5. Y. Cai and T. Li, Statistics and analysis of fire load in hotel buildings in Tianjin Area, Fire Technique and Products Information, Vol. 4, 24-27, 2008 
6. O. Pettersson, S. E. Magnusson, and J. Thor, Fire Engineering Design of Steel Structures, Publication 50, Swedish Institute of Steel Construction, Stockholm, 1976

7. J. O. Bryson and D. Gross, Techniques for the Survey and Evaluation of Live Floor Loads and Fire Loads in Modern Office Buildings, National Bureau of Standards, Washington, D.C., Dec. 1967

8. S. H. Ingberg, J. W. Dunham, and J. P. Thompson, Combustible Contents in Buildings, Building Materials and Structures Report 149, National Bureau of Standards, Washington, D.C., 1957

9. W. C. Fan, Q. A. Wang, F. H. Jiang, and J. J. Zhou, Concise Textbook of Fire Dynamics, University of Science and Technology of China Press, Hefei, 330-360, 1995

10. Bureau of Indian Standards, IS: 1641-1960, Code of Practice for Fire Safety of Building, 1960

11. X. B. Gao and H. Q. Dong, Data analysis and application of SPSS, Tsinghua University Press, Beijing, 237-362, 2007

12. Z. S. Chen, Statistical information processing based on Matlab7.0 software, Hunan Science and Technology Press, Changsha, 176-265, 2005

13. M. B. Mabin, Report on Fire Loadings, 3rd Pro. Study Report, Department of Civil Engineering, University of Canterbury, Christchurch, 1994

14. C. R. Barnett, Pilot Fire Load Survey Carried Out for the New Zealand Fire Protection Association, MacDonald Barnett Partners, Auckland, 1984

15. P. Narayanan, Fire Severities for Structural Fire Engineering Design, Study Report No. 67, Building Technology Ltd, Porirua, 1994

16. Z. H. Sun, B. Yao, and J. H. Sun, Application of Design Fire and Fire Hazard Degree Analysis in Hazard Identification of Performance-Based Fire Protection Design, Fire Safety Science, Vol. 13, NO. 2, 106-110, Apr. 2004

17. K. Kawagoe, Fire Behavior in Room, Report 27, Building Research Institute, Ministry of Construction, Tokyo, 1958

18. Y. P. He, M. Horasan, P. Taylor, and C. Ramsay, A Probabilistic Fire Safety Engineering Assessment of a Refurbished High Rise Office Building, Proceedings of the International Conference on Engineered Fire Protection Design, Society of Fire Protection Engineers, 211-228, June, 2001

19. British Standards Institution, BSI DD 240: Fire safety engineering in buildings, 1997

20. W. C. Fan, J. H. Sun, and S. X. Lu, Methodology of Fire Risk Assessment, Science Press, Beijing, 239-256, 2004 